AperTO - Archivio Istituzionale Open Access dell'Università di Torino

\title{
Macroeconomic Conditions at Entry and Injury Risk at the Workplace
}

\section{This is the author's manuscript}

Original Citation:

Availability:

This version is available http://hdl.handle.net/2318/1678210

since 2018-10-19T09:11:50Z

Published version:

DOI:10.1111/sjoe.12285

Terms of use:

Open Access

Anyone can freely access the full text of works made available as "Open Access". Works made available under a Creative Commons license can be used according to the terms and conditions of said license. Use of all other works requires consent of the right holder (author or publisher) if not exempted from copyright protection by the applicable law. 


\title{
Macroeconomic Conditions at Entry and Injury Risk at the Workplace*
}

\section{Roberto Leombruni}

University of Turin, IT-10136, Torino, Italy

roberto.leombruni@unito.it

\section{Tiziano Razzolini}

University of Siena, IT-53100, Siena, Italy

tiziano.razzolini@unisi.it

\section{Francesco Serti}

IMT School of Advances Studies, IT-55100, Lucca, Italy

francesco.serti@gmail.com

\begin{abstract}
Using a unique dataset from Italy, we show that the local unemployment rate at entry has a persistent positive effect on severe and non-severe workplace injuries of young workers. Entrants during recessions, although receiving marginally higher entry wages, also experience slower wage growth. The observed pattern in the differences between severe and non-severe injuries indicates that entrants during recession may underreport non-severe workplace injuries. Our findings suggest that workers entering during recession are persistently locked into low quality jobs and that the mix of hazardous tasks endogenously adjusts to the business cycle.

Keywords: work-related accidents; business cycle; young workers JEL classification codes: J28; J60; J81
\end{abstract}

\section{Introduction}

The macroeconomic conditions encountered by workers entering the labor market for the first time may persistently affect their future labor market outcomes. The existing evidence (Oyer, 2006; Genda et al., 2010; Kahn, 2010; Kwon et al., 2010; Oreopoulos

\footnotetext{
*Francesco Serti is also affiliated to the Universidad de Alicante. Financial support from MINECO/FEDER (ECO2015-70540-P) and the Compagnia di San Paolo (TO-Call3-20120119-The Popart Network) is gratefully acknowledged. We thank Antonella Bena, Giuseppe Bertola, Alberto Dalmazzo, Massimiliano Giraudo, Climent Quintana Domeque, Marcello Sartarelli, Jan C. van Ours, Francesco Turino, Anzelika Zaiceva.
}

This article has been accepted for publication and undergone full peer review but has not been through the copyediting, typesetting, pagination and proofreading process, which may lead to differences between this version and the Version of Record. Please cite this article as doi:

$10.1111 /$ sjoe. 12285

This article is protected by copyright. All rights reserved. 
et al., 2012; Brunner and Kuhn, 2014) mainly focuses on the wages prospects of young entrants. Little attention has been devoted to other non-pecuniary determinants of job quality, such as the level of workplace safety. These job attributes may represent an important channel of adjustment to negative shocks, particularly in contexts where wages are rigid and regulated by strict institutional rules.

This paper studies the impact of unemployment at entry on workplace safety for a sample of young Italian-born, low- and medium-skilled men who began their first employment between 1994 and 2003. We use a unique dataset that combines work histories from Italian administrative data (Work Histories Italian Panel, WHIP) with individual work-related injuries from the Italian Workers' Compensation Authority (INAIL).

Our main finding is that negative labor market conditions at entry are associated with a persistent increase in work-related accidents. This effect cannot be simply attributed to a lower accumulation of experience and/or tenure, as we find no significant effect of initial conditions on time worked (conditional or unconditional on being employed) and find very small negative effects on tenure only in the long run. Our results are robust to restricting the analyses to severe injuries, which, due to their consequences and immediate care needs, are not subject to reporting bias (Boone and van Ours, 2006; Boone et al., 2011), and to using as a dependent variable a measure of the risk imposed by the working environment, which is not affected by either workers' behavior in the job or variations of firms' injury prevention investments over the business cycle.

An analysis based only on earnings could be particularly misleading in labor markets, such as the Italian one, that are characterized by downward wage rigidity and a large

This article is protected by copyright. All rights reserved. 
shadow economy (approximately $23 \%$ of Italian official GDP, according to Orsi et al., 2014). In these economies, recessions may push relatively less productive workers into the underground economy, leaving only better-paid workers in the formal sector. Indeed, by using the Survey on Household Income and Wealth (SHIW), we find that the likelihood of a young worker beginning her career in an informal (low-paid) job increases significantly during recessions. We show that this a selection mechanism could explain why, in the administrative dataset, we observe that workers who entered during recessions receive slightly higher average entry wages. To the extent that working conditions and wages are relatively worse in the underground economy, our results should provide a lower bound estimate of the impact of starting conditions on the time spent by new workers in lowquality jobs offering relatively fewer career prospects.

Using a canonical graphical analysis, we show that our findings are consistent with a scenario in which entrants during recessions become relatively more willing to bear risk, and firms react by offering wage-job safety bundles characterized by a lower compensation for risk. In the presence of downward wage rigidity, these endogenous responses to recessions are able to explain both the higher average wages and injury risk observed in the formal sector and the detected countercyclical pattern of the underground economy.

Finally, our evidence on lower levels of job safety represents an unexplored channel through which unfavorable initial conditions may negatively affect workers' health status (Maclean, 2013). Moreover, our findings contribute to the literature on the relation between reporting behavior and the business cycle. Analyzing injury dynamics by their severity reveals that worker reporting behavior, in addition to being affected by the

This article is protected by copyright. All rights reserved. 
contemporaneous economic cycle, also depends on the starting conditions.

The remainder of the paper is organized as follows. The next section reviews the economic literature on the effect of adverse conditions at entry. Section III describes the data. The econometric framework and the empirical results are presented and discussed in Section IV. Section V concludes.

\section{Related literature and theoretical background}

The previous literature has mainly investigated the effect of high unemployment at entry on pecuniary labor market outcomes for countries characterized by greater wage flexibility than the Italian labor market. The bulk of these studies focus on entrants with at least a college education in North America (Oyer, 2006; Genda et al., 2010; Kahn, 2010; Oreopoulos et al., 2012) and detect a wage penalty for those who entered during recession that vanishes in approximately ten years. However, for a sample of Austrian low- and medium-skilled workers, Brunner and Kuhn (2014) find an increasing negative effect of the initial unemployment on wages. Genda et al. (2010) detect a negative and persistent impact of unemployment at entry on earnings for low- and medium-skilled Japanese workers but not for their US counterparts; they also argue that institutional differences (i.e., stronger employment protection legislation in Japan coupled with a school-based hiring system) may contribute to this result. Finally, Maclean (2013) shows that, for US middle-aged men, leaving school in a recession decreases mental and physical health.

With labor market rigidities, adverse conditions at entry are more likely to affect outcomes such as employment (Raaum and Røed, 2006) or other non-pecuniary characThis article is protected by copyright. All rights reserved. 
teristics rather than wages. The Italian labor market is an interesting case to study the effect of unfavorable initial conditions since, among European countries, Italy ranks the highest in terms of employment protection legislation, wage compression and downward wage rigidity as well as in terms of centralized wage bargaining and trade union coverage (OECD, 1999,2004). Thus, adjustments to economic downturns may reasonably produce negligible effects on wages and occur through alternative channels such as job safety.
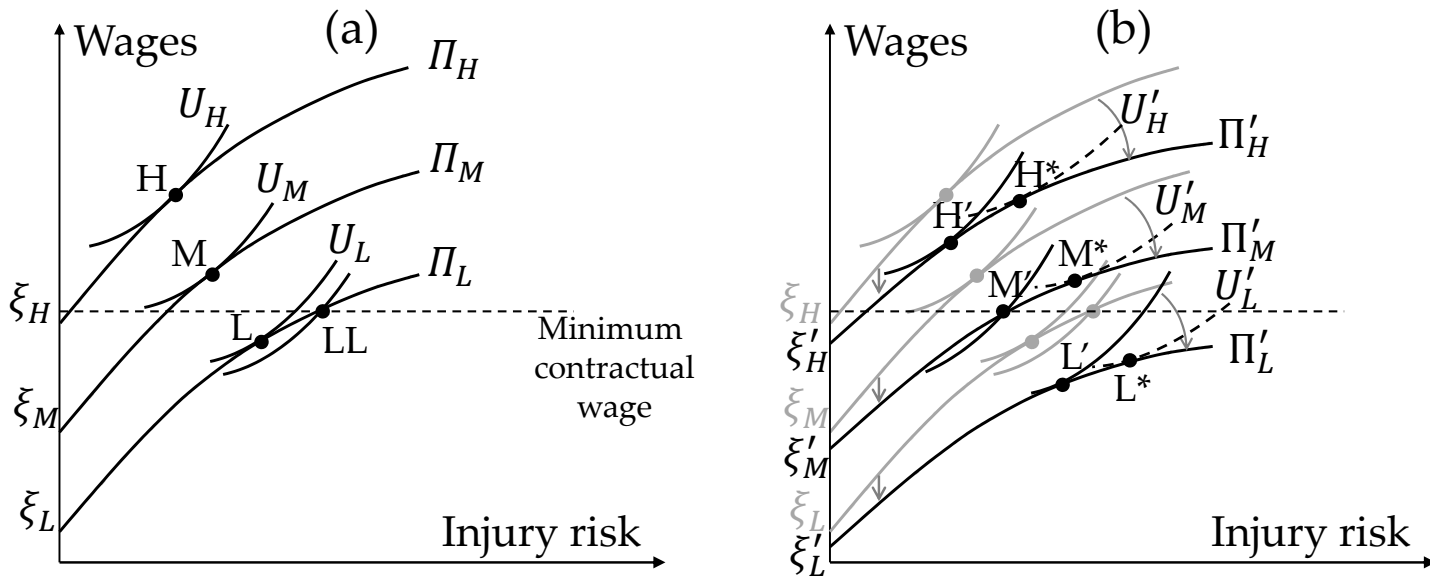

Figure 1: Optimal combinations of wages and injury risk along the business cycle

Note: The figure shows the optimal combination of wages and injury risk in a given job for heterogeneous workers as the tangency points between isoprofit curves $\Pi_{P}(w, i n j)$ and utility curves $U_{P}(w, i n j)$, with $P=H, M, L$. Panels (a) and (b) represent the equilibria in the good and bad state of the economy, respectively.

To develop this intuition, in Figure 1, we describe the optimal combinations of wages and injuries that may emerge in equilibrium during different states of the economy for three types of workers who differ in their level of earning potentials: high, $\xi_{H}$, medium, $\xi_{M}$ and low, $\xi_{L}$. Given the presence of wage rigidities and centralized wage bargaining in the Italian labor market, we assume that each job has a minimum contractual wage (i.e., the dashed horizontal lines in the two panels of Figure 1). However, employers do have some discretion in offering different market opportunities to workers according to

This article is protected by copyright. All rights reserved. 
their earning potentials. This heterogeneity in market opportunities reflects unobserved differences that cannot be fully captured in our empirical analysis even after controlling for observed job, employer and firm characteristics (e.g., workers' productivity). We denote the isoprofit curves as $\Pi_{P}(w, i n j)$ and the utility curves as $U_{P}(w, i n j)$, with $P=H, M, L$. In panel (a) we show that, even in the presence of a positive compensation for risk $(\partial \Pi / \partial i n j>0)$, more productive workers (types $\mathrm{H}$ and $\mathrm{M})$ are paid more by the firm than type $\mathrm{L}$ workers and can cede a portion of their salary in exchange for more workplace safety. ${ }^{1}$ Thus, we have types $\mathrm{H}$ and $\mathrm{M}$ workers exhibiting higher wages and lower injury risk than type $\mathrm{L}$ workers. We assume that this situation is typical in a strong state of the economy when certain combinations (points $\mathrm{H}$ and $\mathrm{M}$ ) are above the minimum contractual wage, and others are represented by a corner solution (point LL).

In panel (b), we assume that recessions may have two effects. First, the recessions reduce the earning potentials of all workers $\left(\xi_{H}^{\prime}, \xi_{M}^{\prime}\right.$ and $\left.\xi_{L}^{\prime}\right)$, thus leading to a downward shift in the isoprofit curves. Second, the recessions induce a change in the slope of the isoprofit curves. The latter effect is essentially similar to the scenario proposed by Viscusi and Hersch (2001) in which segmented labor groups face market opportunities with different wage-risk trade-offs. ${ }^{2}$ In other words, distressed firms may offer flatter combinations of wages and risk (i.e., the isoprofit curves, $\Pi_{P}^{\prime}(w, i n j)$ in panel b) because they realize that, during downturns, entrants may accept a reduction in workplace safety

\footnotetext{
${ }^{1}$ This explains why empirical analyses display a negative correlation between wages and injuries even after controlling for observable worker, job and firm characteristics (see among others Hamermesh, 1999).

${ }^{2}$ Viscusi and Hersch (2001) study differences in workplace risk between smokers and non-smokers. They assume that market opportunities offered by employers to smokers are flatter than those offered to non-smokers (i.e., with lower premia for risk). In our scenario, segmentation is not related to an individual attribute but to labor market conditions. We are grateful to Joni Hersch for having indirectly suggested the possibility of this difference in the wage-risk trade-off.
}

This article is protected by copyright. All rights reserved. 
(i.e., entrants' have flatter utility curves shown by the dashed curves $U_{P}^{\prime}(w, i n j)$ in panel b). Thus, new combinations can occur for high and medium productive workers at $H^{\prime}$ and $M^{\prime}$, if only isoprofit curves flatten, and at $H^{*}$ and $M^{*}$ if the slope of utility curves also decreases. These changes in market opportunities are in accordance with the assumptions made by Gibbons and Waldman (2006) that, during slowdowns, employers create a higher proportion of low level positions. ${ }^{3}$ Isoprofit and utility curves may also flatten in a recession because of the strong insider-outsider dualism characterizing the Italian labor market (i.e., wage rigidity, centralized wage bargaining, high employment protection and union coverage). In this setting, trade unions are expected to exert strict control over the job contract characteristics of entrants, such that insiders could remain protected against macroeconomics shocks, and their jobs could not be threatened by wage underbidding. ${ }^{4}$ Entrants may be requested to bear the consequences of unfavorable macroeconomic conditions by paying a higher price in terms of workplace risk, which they may consider a fair investment to become future insiders. Nevertheless, in an insideroutsider context, the hazardous tasks assigned to young workers should continue to receive positive compensation for risk to not represent a threat to insiders.

The example of panel (b) in Figure 1 shows that, if during a recession isoprofit curves sufficiently flatten, the optimal combinations of wages and injuries for low productivity workers will lie below the minimum contractual wage (points $L^{\prime}$ or $L^{*}$ ); no amount of

\footnotetext{
${ }^{3}$ In the task-specific human capital model of Gibbons and Waldman (2006), wage represents the unique index of the quality of the job. In our setting, a reduction in the quality of jobs offered during a recession can be driven by an increase in the number of hazardous tasks at a given level of wage or by a decrease in the premium/remuneration of risk at any level of wage.

${ }^{4}$ In a typical insider-outsider dualism (Lindbeck and Snower, 2001), entrants are very unlikely to be hired on terms that oppose insiders' interest.
}

This article is protected by copyright. All rights reserved. 
injury risk would compensate for their low level of productivity at the minimum wage. These workers can be profitably hired only in the shadow economy, which is characterized by wages below the minimum wage and by relatively unfavorable job safety conditions. ${ }^{5}$ Thus, Figure 1 illustrates that workers entering the formal sector during recessions are positively selected. To the extent that both the isoprofit and the utility curves sufficiently flatten, these workers will display, as expected, higher average wages, but they will be assigned to lower-quality jobs characterized by higher average injury rates. However, Figure 1 constitutes a static picture. These unfavorable entry outcomes may have long-lasting consequences on the career prospects of entrants. According to Gibbons and Waldman (2006), new entrants facing poor macroeconomic conditions are assigned to lower quality tasks that offer relatively fewer opportunities for accumulating the skills necessary for career progress. The lower transferability of these accumulated skills to higher-level occupations negatively affects actual workers' productivity. Moreover, including the employers' imperfect information about worker productivity could rationalize a persistent effect of the initial conditions. Prospective employers could perceive the initial low-rank job as a signal of the workers' ability, without considering the macroeconomic conditions at the time of labor market entry (Oyer, 2006). Oreopoulos et al. (2012) show that a standard job-search model, augmented with mobility costs that increase with job tenure or age, is also consistent with the persistent effects of unfavorable initial conditions. If the benefits of searching are sufficiently low (or the mobility costs increase sufficiently steeply with age), the catch-up of unlucky entrants may terminate before the gap is closed. Fi-

\footnotetext{
${ }^{5}$ This is consistent with the observed countercyclicality of the share of entrants in the underground economy.
}

This article is protected by copyright. All rights reserved. 
nally, a persistent effect of macroeconomic conditions at entry is also consistent with the existence of implicit/insurance contracts (e.g. Harris and Holstrom, 1982; Beaudry and DiNardo, 1991). Workers entering the labor market during recessions may tend to accept long-term contracts characterized by lower wage growth and may encounter mobility costs. All of these mechanisms of persistence may be reinforced by labor market rigidities, which may contribute to perpetuating the segmentation between lucky and unlucky generations. Indeed, Kawaguchi and Murao (2014) show that, with strict EPL and high union coverage, the persistence of the effects of recession is relatively stronger.

\section{Data Description}

We use the WHIP-Salute database, which merges together data on work careers derived from the administrative records of the National Social Security Administration (INPS), with data on work injuries derived from the administrative records of the National Work Injuries Insurance Administration (INAIL) (Bena et al., 2012). The target population includes employees who worked in the private non-agricultural sector in Italy in the 19852003 period, from which a $6 \%$ random sample has been extracted. Career data provide job start and job end dates, in addition to the actual duration in weeks of each employment relationship. The data also provide information on worker characteristics (age, sex, birthplace, place of work and type of occupation), standard labor market outcomes (number of weeks worked in a year and annual earnings) and characteristics of the firms in which individuals are employed (number of employees, sector and firm age). Weekly wages are computed as the ratio between annual deflated earnings and the number of This article is protected by copyright. All rights reserved. 
weeks worked in a year, with both variables measured on a full-time equivalent scale.

The INAIL dataset contains the date of workplace injuries (i.e., accidents that have occurred during a work task), the duration of injury-related leave at the employer-employee level and a description of the type of injury. The dataset includes all injuries, certified by physicians, leading to a leave of more than three days for the 1994-2003 period. ${ }^{6}$ Using the information on the diagnosis, we adopt a classification that distinguishes immediate care (IC) injuries from the non-immediate care (NIC) ones. The former identify workplace accidents that require immediate treatment at a hospital and therefore cannot be subject to reporting bias (Boone and van Ours, 2006).

We selected Italian-born men $^{7}$ who had their first labor market experience between 1994 and 2003 and who were under 24 years old at the time of entry. We define "first-time labor market entrants" as those workers who are observed for the first time in the sample in 1994 or later. $^{8}$ As the WHIP-Salute dataset does not adequately cover the public sector, we also exclude labor market entrants and employment spells in those industries. ${ }^{9}$ The resulting sample is representative of $70 \%$ of first time labor market entrants in Italy during the 1994-2003 period. Although no information on schooling is available in the data, the restriction on age in practice excludes individuals with higher education/skills

\footnotetext{
${ }^{6}$ Shorter healing periods do not involve INAIL but are the responsibility of the firm, according to collective contract agreements.

${ }^{7}$ The restriction on gender is targeted to reduce the unobserved heterogeneity that reflects the complexity of female labor supply behavior over the life cycle.

${ }^{8}$ We can observe the labor market history of individuals from 1985 to 2003. By considering entrants who are under 24 years old at the time of entry, we exclude the pre-1971 birth cohorts.

${ }^{9}$ The following ATECO 1991/ISIC rev 1.1 codes are omitted from the analysis: L, M, N, O. This barely affects the representativeness of the data. Indeed, only $4.9 \%$ of the selected labor market entrants begin their career in the public sector, and only $4.7 \%$ of individuals in the final sample have job spells in the public sector. Finally, because of its high degree of seasonality and undeclared work, we checked that our results are robust to excluding employment spells in the construction sector.
}

This article is protected by copyright. All rights reserved. 
(i.e., with at least a university degree $)^{10}$ and therefore reduces the potential unobserved heterogeneity problems related to this important dimension. Moreover, job safety should be less relevant for labor market entrants with higher education who tend to perform non-manual tasks. Therefore, due both to data limitations and for conceptual reasons, we concentrate on low- and medium-skilled entrants.

In accordance with the literature, we use unemployment rates to proxy for the economic cycle. In particular, we use data on regional unemployment rates for all workers over the 1985-2003 period from the Italian National Institute of Statistics (ISTAT). The slowdown of the Italian economy after 1993 resulted in an increasing trend in unemployment until 1998. A recovery occurred thereafter. Italian regions markedly differ in the level of unemployment, with the South lagging the developed North. However, to take into account the unobserved heterogeneity connected to the different entry cohorts and the different regional labor markets, our identification strategy is conditional on the region of entry and on the year of entry.

\section{Effects of Macroeconomic Conditions at Entry}

\section{Estimation Strategy}

We study the effect of initial unemployment rate in the region of entry, $u r_{i 0}$, on various labor market outcomes over time, $y_{i t}$, by adopting the following standard specification (Oreopoulos et al., 2012):

\footnotetext{
${ }^{10}$ According to the AlmaLaurea surveys (www.almalaurea.it/en/), in 2003, only $0.7 \%$ of students who completed their undergraduate studies were 23 years old or younger, with 28 being the average age of graduation. During the previous years included in our sample, the average age of graduation was higher.
}

This article is protected by copyright. All rights reserved. 


$$
y_{i t}=\alpha+\left(\sum_{s=0}^{S} \beta_{s} \mathbf{1}\left[\operatorname{Exp}_{i t}=s\right] u r_{i 0}\right)+\phi u r_{i t}+\psi_{s}+\mu_{b}+\lambda_{r}+\gamma_{l}+\theta_{t}+u_{i t}
$$

In addition to introducing unrestricted fixed effects for years of potential experience, $\psi_{s}$, we interact unemployment at entry in region $r$ with dummies specific for each year of potential experience. Thus, the effect of the unemployment at entry is allowed to be different at each year of potential experience: $\beta_{s}$ represents the marginal effect of the initial unemployment rate $s$ years after entry. To isolate the effect of the initial labor market conditions from subsequent macroeconomic shocks possibly correlated with initial conditions, we control for the current regional employment rate, $u r_{i t}$. To the extent that region-cohort specific variations in unemployment rates at entry are not correlated with unobserved traits of entrants, the estimated $\beta_{s}$ s will be exclusively driven by variations in labor demand conditions, and will deliver an unbiased estimate of the effects of recession on entrants' outcomes (Oreopoulos et al., 2012). Although we take into account several sources of unobserved heterogeneity (connected to potential experience, $\psi_{s}$, the region of birth, $\mu_{b}$, the region of entry, $\lambda_{r}$, the year of entry cohort, $\gamma_{l}$, and the calendar year, $\left.\theta_{t}\right)$, entrants encountering different demand conditions may not be fully comparable in terms of unobserved characteristics. Therefore, we also present the results obtained by augmenting the above baseline specification with additional controls related to the entry job (i.e., type of occupation such as apprentice, ${ }^{11}$ blue collar, white collar, manager, as well as firm sector, size and age). Finally, we implement various robustness checks to investigate how our findings are likely to be affected by endogenous labor market entry,

\footnotetext{
${ }^{11}$ Apprenticeship is a form of temporary employment contract for workers under age 26 .
}

This article is protected by copyright. All rights reserved. 
both from the perspective of the timing of entry and sorting into different labor markets. ${ }^{12}$

\section{Main Results}

We first focus our analysis on standard labor outcomes such as log weekly wages, log annual earnings and log annual weeks worked. We also use all observations in the 19942003 period to construct an index to measure the log mean wage in occupations in the same sector. By using this index as a dependent variable, we can detect the movement of workers in occupations receiving higher or lower salaries on average. Figure 2 shows the estimated effect of $u r_{0}$ by year of experience on the log weekly wages, the log wage index, the log annual earnings and the log of weeks worked. ${ }^{13}$

Panel (a) indicates that a one-point increase in the unemployment rate is associated with an increase in starting wage levels by $1.6 \% .{ }^{14}$ However, during periods of high unemployment, entrants display a relatively lower wage growth. Indeed, the initial premium decreases rapidly and fades away after 7 years of experience. The results in Panel (b) focus on the log wage index and indicate that entrants during recessions are more likely to start in occupations that receive higher compensations on average. The effect of $u r_{0}$ on the log wage index is more persistent than the effect on the individual wages, thus suggesting that these cohorts of workers may have lower mobility rates from these occupations. Panels (c) and (d) confirm the presence of a marginal premium also in terms

\footnotetext{
${ }^{12}$ To fully exploit all the available information about the timing of the occurrence of injuries, we have also repeated the analysis within a duration framework. As shown in section A.3.4 of the Online Appendix, the results we obtained are very similar to those presented in the main text.

${ }^{13}$ The detailed estimation results corresponding to the Figures shown in the paper are reported in the Online Appendix.

${ }^{14}$ Using data from the Labor Force Survey we find no correlation between the local unemployment rates and the overtime hours of young workers.
}

This article is protected by copyright. All rights reserved. 
(a) Log weekly wages

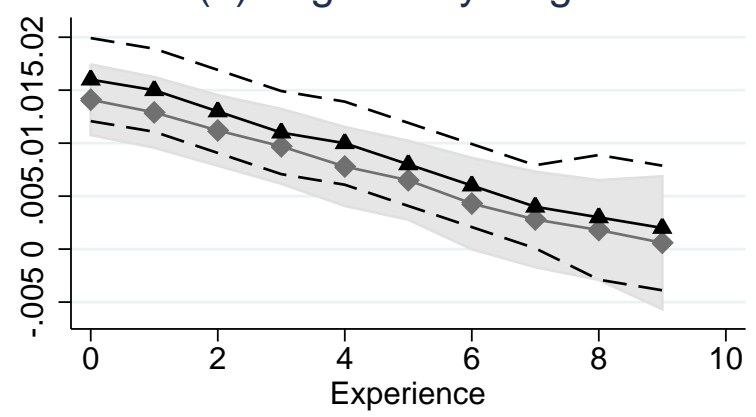

(c) Log annual earnings

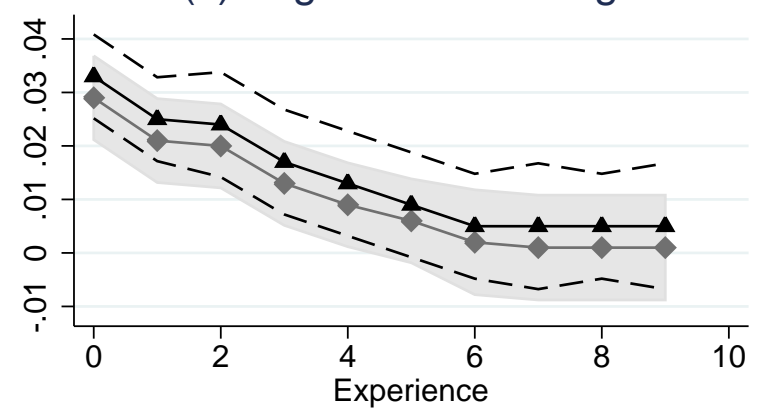

(b) Log wage index

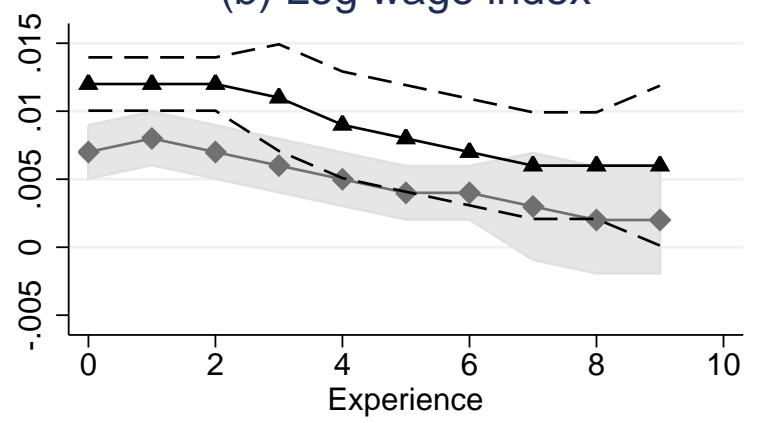

(d) Log annual weeks worked

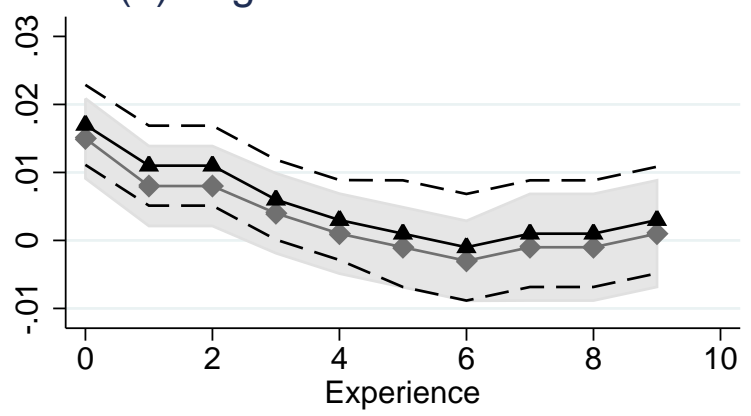

\section{$\longrightarrow$ baseline specification $\_$with additional controls}

Figure 2: The effect of unemployment rate at entry on pecuniary outcomes

Note: The figure shows the effect of unemployment at entry $\left(u r_{0}\right)$ by year of experience (i.e., the parameters $\beta_{s}$ of elements $\mathbf{1}\left[\operatorname{Exp}_{i t}=s\right] \times u r_{i 0}$ in equation 1) on the following dependent variables: $\log$ weekly wages in panel (a); log wage index in panel (b); log annual earnings in panel (c); log annual weeks worked in panel (d). The sample in the baseline specification consists of 362,682 observations of Italian-born men who had their first labor market experience between 1994 and 2003 and who were under 24 years old at the time of entry. The sample size in the regression with additional controls reduces to 349,680 due to missing values. Connected triangles represent the effect of $u r_{0}$ by year of experience in the baseline specification which includes as controls the current unemployment rate $\left(u r_{i t}\right)$ and dummy variables for: calendar year $\left(\theta_{t}\right)$, years of potential experience $\left(\psi_{s}\right)$, region of birth $\left(\mu_{b}\right)$, region of entry $\left(\lambda_{r}\right)$, year of entry cohort $\left(\gamma_{l}\right)$. Connected diamonds represent the effect of unemployment at entry $\left(u r_{0}\right)$ by year of experience when the following characteristics of the first firm and job are added to the baseline specification: dummies for sector and type of occupation (apprentice, blue collar worker and white collar worker), firms' average number of employees and age. The detailed estimation results are available in Tables A2 and A5 in the Online Appendix. Standard errors are clustered by region of entry per year of entry. The dashed lines and the gray area show the $95 \%$ confidence intervals for the baseline specification and the specification with additional controls, respectively.

This article is protected by copyright. All rights reserved. 
of annual earnings and weeks worked, which become insignificant after 6 and 4 years, respectively.

Figure 3 displays the pattern of the estimated effects of initial unemployment rate on certain proxies of job safety by year of potential experience. In panels (a), (b) and (c) the dependent variables are the number of injuries (injuries of any kind, IC injuries and NIC injuries) suffered by a worker divided by the number of full-time equivalent paid weeks. With this normalization, we are able to take into account heterogeneity in the exposure to risk. In addition, these variables are expressed as the number of injuries per thousand days worked to improve the readability of the estimates (i.e., to reduce the number of decimals). However, variation in injuries at the individual level may be determined by factors other than the risk imposed by the work environment but that are otherwise connected to starting macroeconomic conditions. Indeed, a higher unemployment rate at entry may induce workers to exert greater effort and/or it may constitute a stress factor leading to less cautious behavior. Ideally, a measure of the risk imposed by the working environment may be constructed by using the number of workplace injuries incurred by the colleagues of young entrant "i" in each firm; however, this strategy is not feasible because the WHIP dataset does not contain information on all workers employed at a single firm. Therefore, at a level of greater aggregation, three injury indexes have been computed (i.e., one for each category of injuries: all, IC and NIC) as the sum of injuries in the 1994-2003 period divided by the corresponding sum of weeks worked in cells defined using occupation (blue versus white collar), sector (ATECO 1991/ISIC rev 1.1 at two digits) and region. These injury incidence rates have been computed using workers over

This article is protected by copyright. All rights reserved. 
(I) Injuries at the individual level
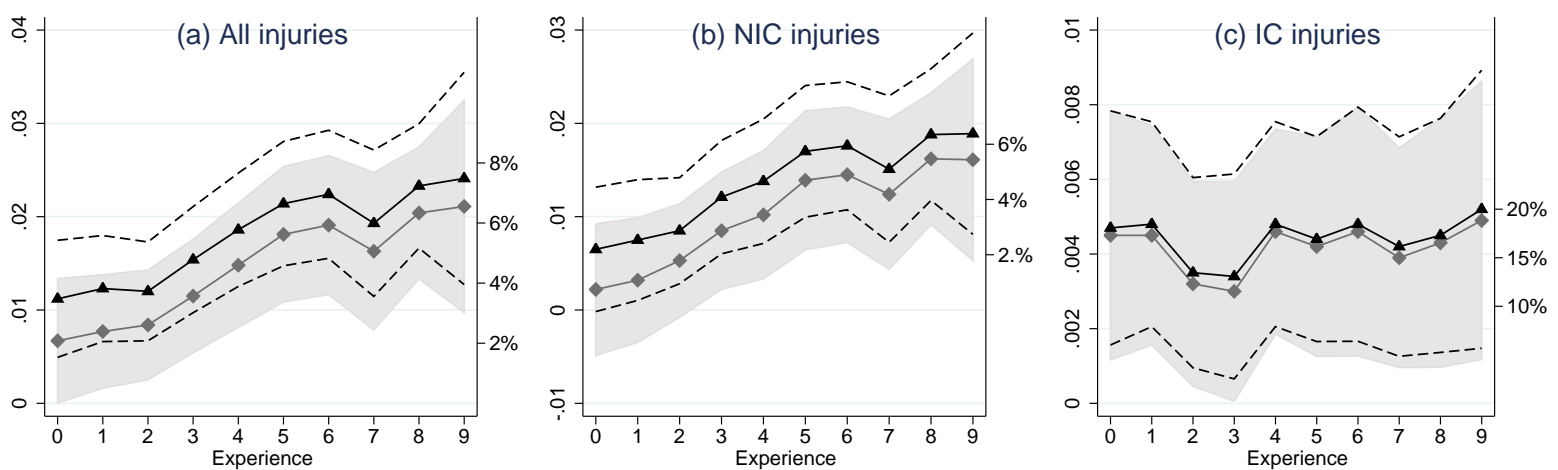

(II) Injury incidence rates
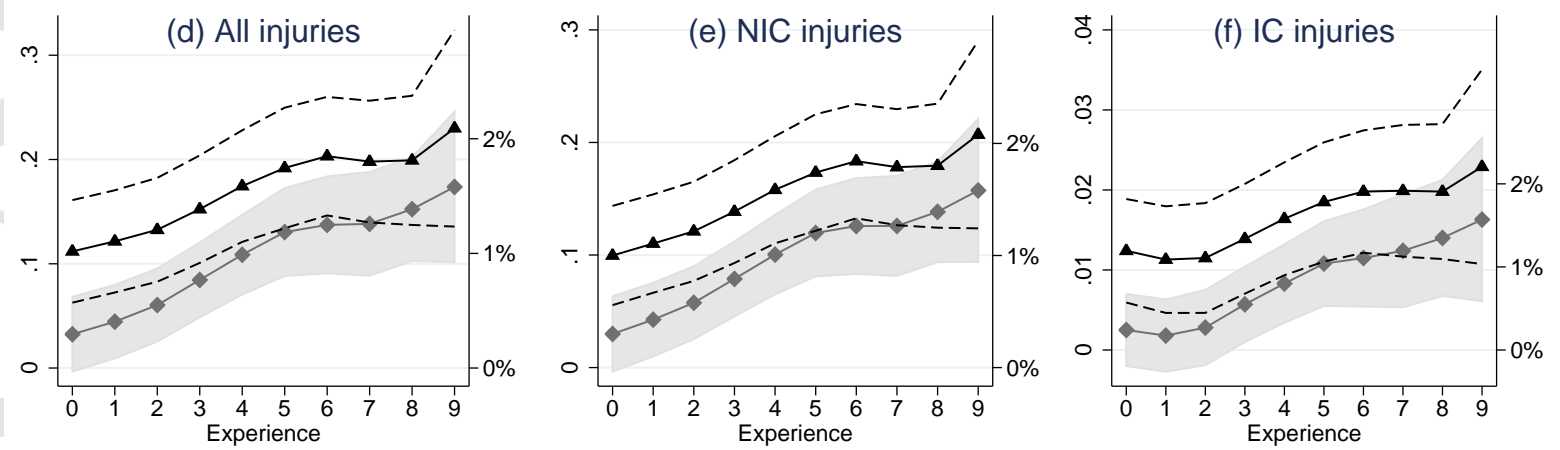

$\longleftarrow$ baseline specification $\longleftarrow$ with additional controls

Figure 3: The effect of unemployment rate at entry on individual level injuries and injury

\section{incidence rates}

Note: The figure shows the effect of unemployment at entry $\left(u r_{0}\right)$ by year of experience (i.e., the parameters $\beta_{s}$ in equation 1) on two types of dependent variables: I) workplace accidents at the individual level (expressed as the number of injuries per thousand days worked) for all injuries, non-immediate care injuries (NIC), and immediate care injuries (IC) in panels a, b and c, respectively; II) Injury incidence rates computed as the sum of injuries in the 1994-2003 period divided the corresponding sum of weeks worked in cells defined using occupation (blue versus white collar), sector (ATECO 1991/ISIC rev 1.1 at two digits) and region. These workplace indexes have been computed using workers over 34 years old for all injuries, non-immediate care injuries (NIC), and immediate care injuries (IC) in panels d, e and $f$, respectively. The number of observations for individual injuries is the same as in Figure 2; due to cells missing values, for the incidence rates it decreases to 349,379 and to 342,251 in the baseline and in the additional control specification, respectively. The right vertical axis expresses these effects as a percentage of the sample mean of the corresponding dependent variable. Connected triangles and connected diamonds represent the effects of $u r_{0}$ by year of experience in the baseline specification and in the specification with additional controls, respectively (see the note to Figure 2 for information on the controls used in the two specifications). The detailed estimation results are available in Tables A3 and A6 in the Online Appendix. Standard errors are clustered by region of entry per year of entry. The dashed lines and the gray area show the $95 \%$ confidence intervals for the baseline specification and the specification with additional controls, respectively.

This article is protected by copyright. All rights reserved. 
34 years old to obtain a measure of risk totally independent of the behavior of young entrants. The value of the indexes calculated for older workers is then imputed to entrants belonging to the same cell. In panels (d), (e) and (f), we use these three injury incidence rates as dependent variables to determine the effect of $u r_{0}$ on the occupation-specific risks faced by workers along their careers. To gauge the economic relevance of the estimated effects, the right axis of each panel of Figure 3 reports the range of the estimated effects in percentage terms; these are obtained by dividing the estimated effects (reported in the left axis) by the sample average of the corresponding dependent variable. ${ }^{15}$

Panels (a), (b) and (c) in Figure 3 indicate a positive and significant effect of $u r_{0}$ on the number injuries (per thousand days worked) at the individual level, which increases over time for all injuries and NIC injuries but remains constant for IC injuries. Compared to the average number of injuries observed in the sample, the estimated effect of a one-point increase in $u r_{0}$ on the number of all injuries ranges from $3.5 \%$, during the first year, to $7.5 \%$ when workers have potentially accumulated ten years of experience. When we restrict the analysis to NIC injuries, the estimated percentage effects are lower, but their temporal pattern increases more steeply (from $2.2 \%$ to $6.4 \%$ ). Instead, for the estimated percentage losses in terms of IC injuries, which are of a greater magnitude (in the range $13 \%-20 \%$ ), we are unable to reject that they are constant over time. The different magnitude and temporal pattern for IC and NIC injuries suggest that the reporting behavior may depend on initial conditions; workers beginning their career in a relatively

\footnotetext{
${ }^{15}$ The average number of injuries per thousand days worked is 0.322 . Distinguishing between NIC and IC injuries, this figure is 0.296 and 0.026 , respectively. The average value of the injury incidence rate for all injuries is 10.996. Distinguishing between NIC and IC injuries, this figure is 9.958 and 1.038, respectively.
}

This article is protected by copyright. All rights reserved. 
less favorable macroeconomic scenario may have a worse bargaining position within the firm and may tend to underreport less serious injuries. This difference in reporting behavior may decrease as workers accumulate experience and their bargaining positions equalize. The absence of underreporting of IC injuries could explain why we find greater percentage losses in terms of this type of injury. It is also worth noting that, in accordance with Boone and van Ours (2006) and Boone et al. (2011), the effect of the current unemployment rate is negative and significant for all injuries and NIC injuries, but it is not statistically significant for IC injuries; ${ }^{16}$ the current economic cycle only affects less serious injuries by changing the incentives to report this type of injury. Therefore, we believe that the effect of the current unemployment rate on injuries mainly reflects the reporting behavior of workers, while the effect of $u r_{0}$, being robust to restricting the analysis to IC injuries, truly implies a lower level of job safety.

Panels (d), (e) and (f) in Figure 3 describe the estimated effect of $u r_{0}$ on the injury incidence rates which, by construction, do not reflect the worker's behavior and effort on the job. The results are qualitatively similar to those obtained by using injuries at the individual level; entrants in recession persistently also lose in terms of injury incidence rates. Therefore, we can exclude that the effects estimated at the individual level are simply due to less cautious behaviors and/or greater effort. Comparing the estimated coefficients to the observed averages of the indexes, the estimated percentage effect of a one-point increase in $u r_{0}$ on the three injury incidence rates is very similar, ranging from $1 \%$ to $2 \%$. The lower magnitude of these estimated percentage effects with respect to what

\footnotetext{
${ }^{16}$ Table A3 in the Online Appendix reports these results in columns 1, 3, and 2, respectively.
}

This article is protected by copyright. All rights reserved. 
we obtain by using individual level injuries, in addition to reflecting relatively less cautious behaviors and greater effort of entrants during recession, could also be due to the coarse nature of these proxies, which are unable to identify differences in injury risk determined by the allocation of entrants to different tasks within cells. Similarly, the absence of relevant differences between the estimates for IC and NIC indexes could be connected to the aggregate nature of these proxies of injury risk, which, by averaging across workers, eliminate differences in reporting behavior related to initial macroeconomic conditions.

To detect whether compositional effects related to observables drive our findings, in Figure 4, we report the results obtained by using workers' job and firm characteristics as dependent variables (i.e., binary indicators for being an apprentice, blue collar and white collar worker in panels a, b and c; average number of employees in panel d) in equation (1). We find that entrants during recession have a constantly higher probability of working in a blue collar occupation (panel b) and a lower probability of working in the more sheltered apprentice position (panel a). Moreover, unfavorable starting conditions negatively affect the probability of being white collar but only in the medium-long run (panel c). Panel (d) indicates that there are no differences driven by initial conditions in firms' size. As shown in Figures 2 and 3, when we introduce initial firm attributes (sector, firm size and firm age) and the type of occupation (apprentice, blue collar and white collar) as additional controls in the main regressions, the estimated effects of the initial unemployment rate on labor market outcomes are not affected. Moreover, the results are not altered by the inclusion of the initial firm's employee growth in previous years, thus suggesting that the cyclical variation in the job-quality is not determined by different types of firms recruiting

This article is protected by copyright. All rights reserved. 
in different stages of the cycle. Similarly, the introduction of initial contractual code dummies as additional controls does not affect the main results either, thus confirming that formal contractual arrangements hide a considerable heterogeneity in job quality that, without the injury data, would not have been detected. ${ }^{17}$
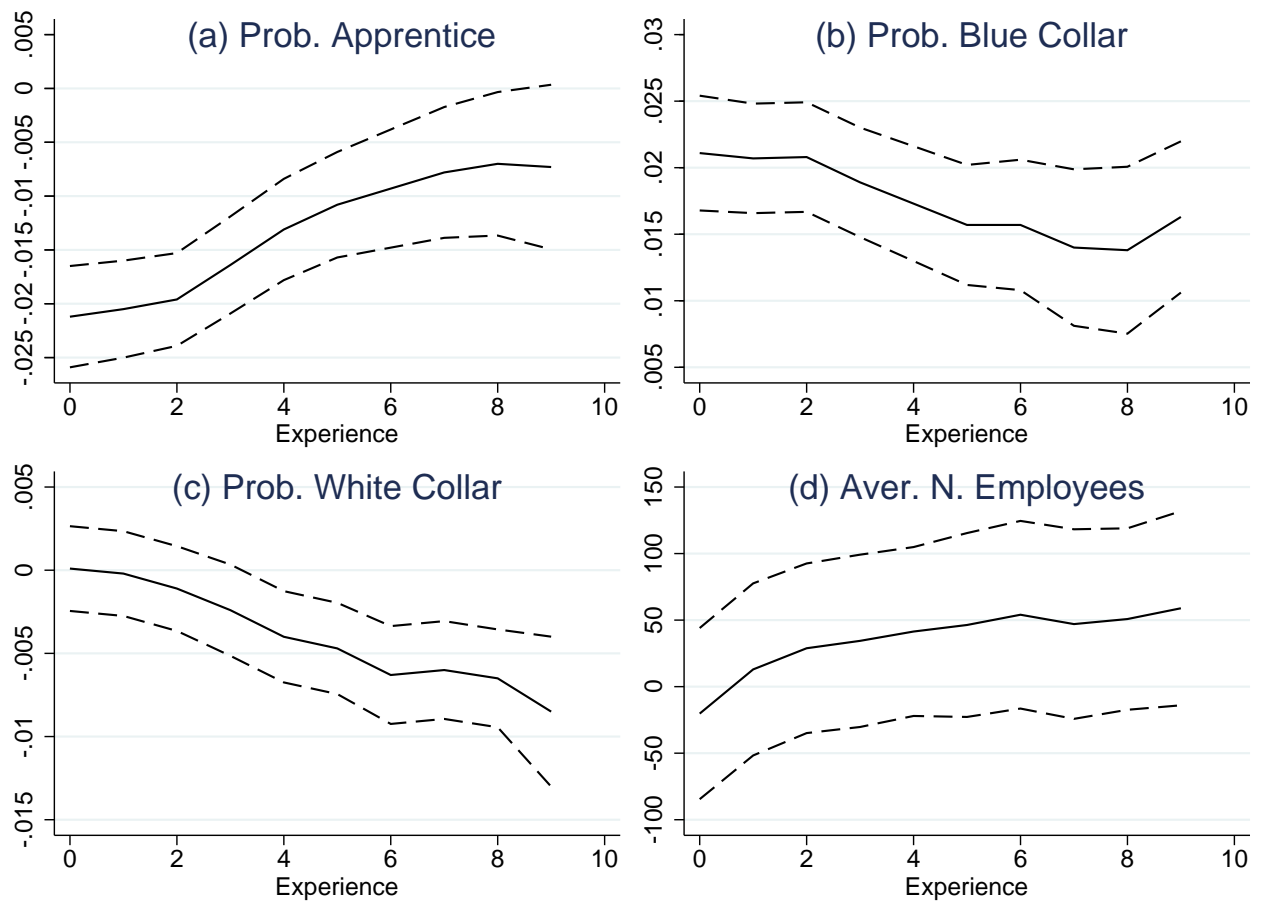

Figure 4: The effect of the unemployment rate at entry on job and firm characteristics

Note: The solid line in the figure shows the effect of unemployment at entry $\left(u r_{0}\right)$ by year of experience (i.e., the parameters $\beta_{s}$ in equation 1) on the following dependent variables related to the worker's job or firm: binary indicators for being an apprentice, blue collar and white collar worker in panels $\mathrm{a}, \mathrm{b}$ and c; average number of employees in panel d. The sample used for the estimations in panels a, b and c consists of 362,682 observations, and it decreases to 345,589 observations in panel d due to missing values. The regressions include as controls current unemployment rate $\left(u r_{i t}\right)$, calendar year effects $\left(\theta_{t}\right)$ and dummy variables for years of potential experience, $\left(\psi_{s}\right)$, for the region of birth $\left(\mu_{b}\right)$, for the region of entry $\left(\lambda_{r}\right)$, for the year of entry cohort $\left(\gamma_{l}\right)$. All estimated coefficients are available in Table A4 in the Online Appendix. Standard errors are clustered by region of entry per year of entry. The dashed lines represent the $95 \%$ confidence intervals.

Therefore, the above evidence tends to exclude an explanation based on firm and job

\footnotetext{
${ }^{17}$ Contractual codes refer to a finer categorization of occupations (with respect to those used as additional controls in Figures 2 and 3). These occupational codes are mainly related to seniority and to automatic career progression and can be hardly used as a proxy of the skills needed in a given task (Colleoni et al., 2009). Estimates with these additional controls are shown in Tables A9 and A11 in the Online Appendix.
}

This article is protected by copyright. All rights reserved. 
observable characteristics.

\section{Entry over the business cycle}

The estimated positive association between local unemployment rates and entry wages within occupations suggests that negative selection of entrants during recessions is unlikely. ${ }^{18}$ This finding is confirmed by Figure 5, which displays the estimated effect of $u r_{0}$ on the percentiles of the log wage distribution for the year of entry and the third, sixth and ninth years of experience. After controlling for the characteristics of the first job and firm, we do not detect negative effects of $u r_{0}$ in any portion of the wage distribution.

Moreover, the observed dynamics of age at entry and educational choices along the business cycle are not consistent with the negative selection of entrants during recessions. Negative selection could occur because "high productivity" potential entrants encountering negative macroeconomic conditions could wait for better opportunities, either by accumulating additional years of education or remaining out of the labor force, or because "low productivity" entrants could be forced to anticipate the entry into the labor market if remaining in education became economically unviable. Therefore, if a process of negative selection of entrants was at work during recessions, one should observe that age at entry and the probability of being in education are negatively associated with the

\footnotetext{
${ }^{18}$ The bulk of the previous investigations examining the effect of entry conditions on wage dynamics provide evidence in favor of positive selection of entrants (or absence of negative selection) during negative macroeconomic conditions (Oyer, 2006; Genda et al., 2010; Kahn, 2010; Kwon et al., 2010; Oreopoulos et al., 2012; Brunner and Kuhn, 2014). Finally, Devereux (2002) finds that firms increase their hiring standards during a recession. This firm behavior may be more relevant in the Italian context characterized by strict employment protection and a strong insider-outsider divide.
}

This article is protected by copyright. All rights reserved. 
unemployment rate. $^{19}$
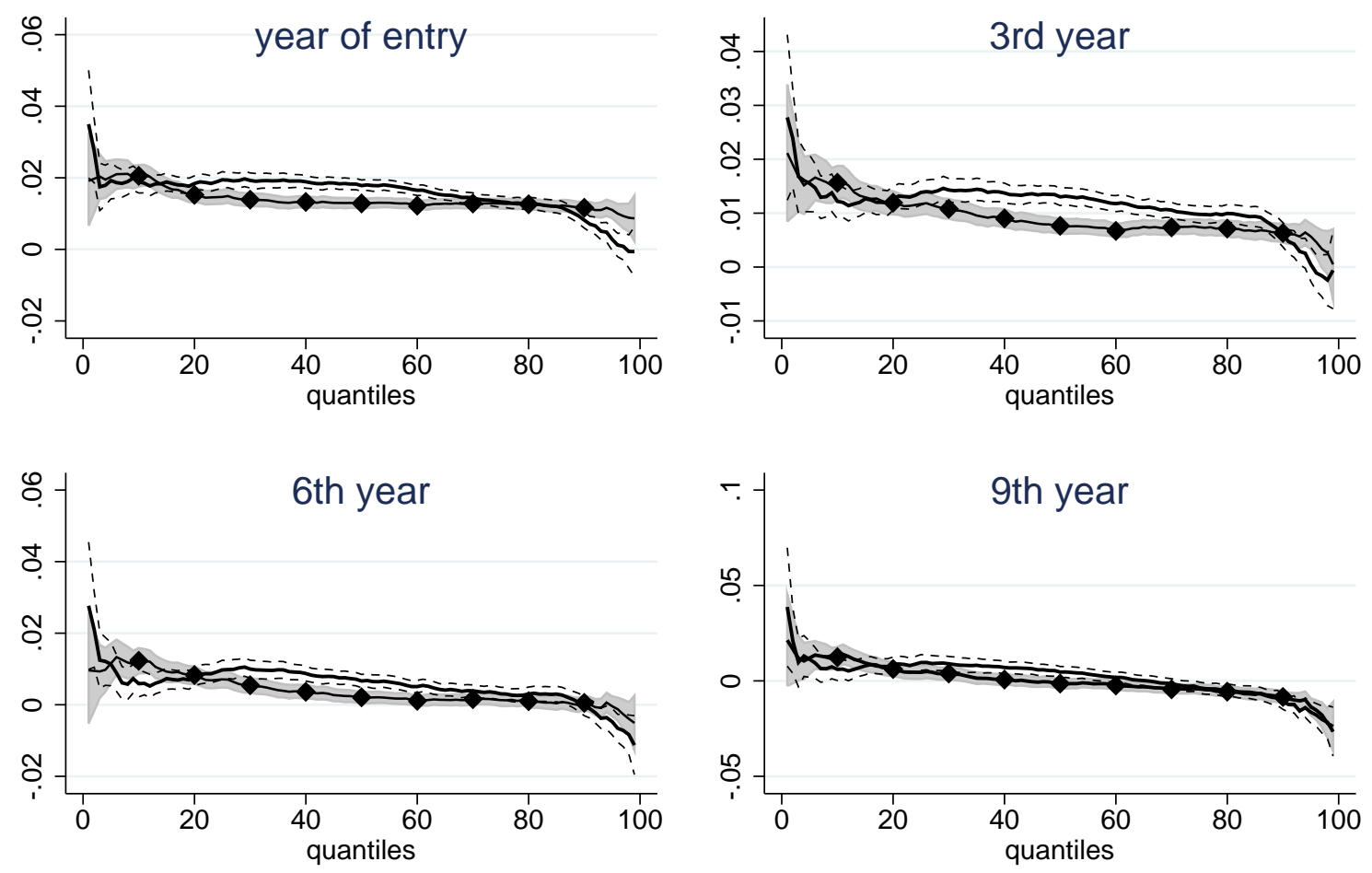

\section{baseline spec. — with additional controls}

Figure 5: The effect of unemployment rate at entry on the log wage distribution

Note: The figure represents the effect of the unemployment rate at entry $\left(u r_{0}\right)$ on the percentiles of the $\log$ wage distribution at the following years of experience: entry year, third year, sixth year and ninth year. The effects correspond to the $\beta_{s}$ coefficients retrieved from the estimation with quantile regressions of specification 1. The black solid line represents the estimated effect of $u r_{0}$ in the baseline specification, which includes as controls current unemployment rate and dummies for year of entry, region of entry, region of birth, current year and experience. The connected diamonds represent the estimated effects of $u r_{0}$ after inclusion in the baseline specification of additional controls for initial firm characteristics (sector, average number of employees and age) and type of occupation (apprentice, blue collar and white collar). The sample in the baseline specification consists of 362,682 observations of Italian-born men who had their first labor market experience between 1994 and 2003 and who were under 24 years old at the time of entry. The sample size in the regressions with additional controls decreases to 349,680 due to missing values. The dashed lines and the gray area show the $95 \%$ confidence intervals for the baseline specification and the specification with additional controls, respectively.

The results of regressing the age of entry on the regional unemployment rate, region

\footnotetext{
${ }^{19}$ In addition, migration of entrants across regional labor markets may react endogenously to differences in regional unemployment rates and lead to selection mechanisms that may affect our results. In section A.3.2 in the Online Appendix, we show that migration decisions are mainly determined by permanent differences in job opportunities between regions and are not driven by the regional business cycle, and we perform robustness checks.
}

This article is protected by copyright. All rights reserved. 
and time dummies are reported in the first column of Table 1. A one percentage point increase in the unemployment rate is associated with an increase of 0.04 years (approximately two weeks) in the average age of entry. Considering that the observed range of variation of the unemployment rate within regions is, on average, approximately 4 percentage points, the size of the estimated effect is tiny. This positive correlation suggests that cohorts entering the labor market during unfavorable conditions tend to be marginally older and, therefore, it is not consistent with negative selection. Although small, the effect of the unemployment rate on the age at entry may be the result of strategic educational choices. ${ }^{20}$ However, the effect may simply reflect delayed entry due to unemployment (which is very high in the Italian context, particularly in the South) or non-employment. Since the education level of entrants is not reported in the WHIP database, we tested the correlation between unemployment and educational choices for our specific sample and time frame by exploiting pooled data from the Italian Labor Force Survey. In the second and third columns of Table 1, we report the results of logistic regressions in which the probability of being a high school and university student is modeled as a function of the regional unemployment rate, also conditioning on age, region and year dummies. The probability of attending high school or that of being a university student are not found to be affected by the current economic cycle. This finding suggests that the slightly higher age of entrants detected during economic contractions should

\footnotetext{
${ }^{20}$ Actually, high unemployment may exert opposite effects on the decision to remain in education: a higher unemployment probability decreases the opportunity cost of the educational investment; however, at the same time, it decreases the returns to education and the resources of families. The evidence is scant for Italy. Carmeci and Chies (2006), who focus on the decision of further education at the end of compulsory education for the 1993-1999 period, find that the level of unemployment rates do negatively influence the decision to invest in further education, but the annual variation in unemployment has a negligible effect.
}

This article is protected by copyright. All rights reserved. 
be imputed to episodes of unemployment/non-employment before entry rather than to

further accumulation of human capital.

Table 1: The effect of labor market conditions on entry decisions

\begin{tabular}{lccc}
\hline \hline & $(1)$ age $_{0}$ & (2) High School student & (3) University student \\
\hline $\mathrm{ur}_{0}$ & $0.044^{* * *}$ & & \\
& $(0.016)$ & & \\
$\mathrm{ur}_{t}$ & & 0.018 & -0.006 \\
& & $(0.034)$ & $(0.006)$ \\
\hline$N$ & 80331 & 143009 & 196150 \\
$($ Pseudo $) R^{2}$ & 0.082 & 0.103 & 0.070 \\
\hline \hline
\end{tabular}

Note: The table reports the effect of labor market conditions on the age at entry $\left(\right.$ age $_{0}$, in column 1) measured using the WHIP-Salute dataset and on indicator variables for being a high school student (column 2) and for being a university student (column 3), measured using the Italian Labor Force Survey on a sample of young workers selected with the criteria explained in section III. All of the regressions include year fixed effects and region fixed effects. The results of column 1 are based on an OLS regression. Columns 2 and 3 report the results of logistic regressions that include age as an additional covariate. $u r_{0}$ refers to the unemployment rate of the region of entry in the year of entry. $u r_{t}$ is the contemporaneous unemployment rate in the region of residence. Standard errors in parentheses are clustered by region per year. Pseudo $R^{2}$ measures are provided for logistic regressions in columns 2 and 3 . $^{* * *}$ significant at $1 \%,{ }^{* *}$ significant at $5 \%,{ }^{*}$ significant at $10 \%$.

To further study the possibility of positive selection mechanisms, we have used the Survey on Household Income and Wealth (SHIW) from the Bank of Italy. The information available in this dataset on the payment of pension contributions allows us to identify formal and informal workers. ${ }^{21}$ Employment in the underground economy is a possible consequence of recessions that cannot be studied with administrative data but may be a relevant phenomenon in the Italian case. We thus replicate the analyses of section IV with the same sample restrictions explained in section III and using a specification similar

\footnotetext{
${ }^{21}$ The exact formulation of the question we use is: "Considering your lifetime work experience, did you ever pay, or your employer pay, pension contributions, even for a short period?" If an individual replies negatively to this question and declares to be employed, it means that she has been working in the underground economy during her entire career (Cappariello and Zizza, 2010).
}

This article is protected by copyright. All rights reserved. 
to equation 1 . The only difference is that, instead of interacting the initial unemployment rate with the experience dummies, here, to diminish the number of estimated parameters, we posit that the effect of the initial unemployment rate is linear in experience. ${ }^{22}$

Table 2: The effect of labor market conditions on pecuniary outcomes. Data from SHIW

\begin{tabular}{lccccccc}
\hline \hline & \multicolumn{2}{c}{$\begin{array}{c}\text { log annual } \\
\text { earnings }\end{array}$} & \multicolumn{2}{c}{$\begin{array}{c}\text { log months } \\
\text { worked }\end{array}$} & \multicolumn{2}{c}{$\begin{array}{c}\text { log monthly } \\
\text { wages }\end{array}$} & $\begin{array}{c}\text { Probability } \\
\text { underground }\end{array}$ \\
sample & $(1)$ All & $\begin{array}{c}\text { (2) Only } \\
\text { formal }\end{array}$ & $(3)$ All & $\begin{array}{c}\text { (4) Only } \\
\text { formal }\end{array}$ & $\begin{array}{c}(5) \text { All } \\
\text { (6) Only } \\
\text { formal }\end{array}$ & $(7)$ All \\
\hline$u r_{0}$ & 0.017 & $0.041^{* *}$ & 0.021 & $0.035^{* *}$ & -0.011 & 0.005 & $0.032^{* * *}$ \\
& $(0.016)$ & $(0.021)$ & $(0.016)$ & $(0.016)$ & $(0.019)$ & $(0.014)$ & $(0.012)$ \\
$u r_{0} \times$ Exper. & $-0.003^{* *}$ & $-0.002^{*}$ & -0.001 & -0.001 & $-0.002^{*}$ & -0.001 & 0.001 \\
& $(0.001)$ & $(0.001)$ & $(0.001)$ & $(0.001)$ & $(0.001)$ & $(0.001)$ & $(0.001)$ \\
\hline$N$ & 1278 & 1135 & 1262 & 1128 & 1262 & 1128 & 1278 \\
$R^{2}$ & 0.304 & 0.284 & 0.177 & 0.183 & 0.215 & 0.209 & 0.151 \\
\hline \hline
\end{tabular}

Note: The table reports the effect of unemployment at entry on log annual earnings (columns 1 and 2), $\log$ months worked (columns 3 and 4), log monthly wages (columns 5 and 6) and a binary indicator variable for being an informal worker (column 7). All variables are measured from the SHIW dataset on a sample of young workers selected with the criteria explained in section III. Columns 1, 3, 5 and 7 use the entire sample of workers (i.e., formal plus informal), whereas columns 2,4 and 6 use only the formal ones. The results are obtained from OLS regressions of the specification: $y_{i t}=\alpha+\psi$ Experience $_{i t}+$ $\delta u_{i 0}+\beta u_{i 0} \times$ Experience $_{i t}+\phi u r_{i t}+\mu_{b}+\lambda_{r}+\gamma_{l}+\theta_{t}+u_{i t}$. In contrast to the specification of equation 1 , we use continuous experience and the effect of $u r_{0}$ is linear in experience. All remaining controls are equal to those in the baseline specification used in Figures 2 and 3. Standard errors in parentheses are clustered by region of entry per year of entry. ${ }^{* * *}$ significant at $1 \%,{ }^{* *}$ significant at $5 \%,{ }^{*}$ significant at $10 \%$.

As shown in column 7 of Table 2, where the dependent variable is an indicator variable for working in the underground economy, a percentage point increase in the unemployment rate at entry is associated with an increment of approximately 3 percentage points in the probability of being employed in an informal job. This effect is persistent over time,

\footnotetext{
${ }^{22}$ Considering the lower number of observations and that we are using survey data, the precision of the estimates should be lower than those obtained by using the WHIP-Salute database. In the SHIW dataset, information on the number of weeks worked in a year is not available.
}

This article is protected by copyright. All rights reserved. 
and it is economically relevant. ${ }^{23}$ Restricting the analysis only to formal workers (i.e., with paid pension contributions), we find a significant positive effect of unemployment at entry on log annual earnings and on log of months worked and a positive effect (although not statistically significant) on log monthly wages (see columns 2, 4 and 6 in Table 2, respectively). These results are consistent with those found in the administrative WHIPSalute dataset. ${ }^{24}$ In contrast, when retaining all workers (formal and informal jobs; in columns 1, 3 and 5) in the sample, we do not find statistically significant effects of unemployment at entry on log of weeks worked and log of annual earnings, and the estimated effect on log of monthly wages becomes negative (although not statistically significant). In the segmented labor market theory, workers enter the informal sector because they are rationed out of the formal sector as a result of an overly regulated labor market. In the formal sector, wages are relatively higher because they are set above market-clearing prices due to minimum wages. According to the SHIW dataset, (after controlling for experience, region of entry, year of entry into the labor market, current year and current unemployment rate) the monthly wage of workers employed in the underground economy is approximately $24 \%$ lower with respect to that of formal workers. ${ }^{25}$ Hence, the positive effect of the unemployment rate at entry on pecuniary outcomes detected in the WHIP-Salute dataset could be due, at least in part, to this countercyclical pattern of the underground economy.

\footnotetext{
${ }^{23}$ Indeed, the observed probability to hold a job in the underground economy is approximately 11 percent. This countercyclicality of the underground economy is consistent with the results of Orsi et al. (2014).

${ }^{24}$ The size and the statistical significance of the estimated effects decrease as workers accumulate labor market experience.

${ }^{25}$ All of the estimated effects remain stable once we also control for all the available firm (size and the sector) and worker (level of education, age at entry, type of occupation and family wealth) characteristics.
}

This article is protected by copyright. All rights reserved. 
If positive selection based on unobserved ability was the only explanation behind our results, the observed increase in average wages for entrants during a recession would be most likely accompanied by a corresponding decrease in average injury risk. However, the observed increase in workplace accidents, together with the anticyclical pattern of selection into the underground economy, may be explained by the endogenous changes in wage offers curves and in entrants' attitudes toward risk outlined in Figure 1. Unfortunately, the coexistence of several sources of unobserved firms' and entrants' heterogeneity do not allow us to disentangle the compositional effects due to the positive selection from changes in market opportunities and preferences (Rosen, 1974).

\section{Effect on workers' mobility and tenure}

Workers' mobility may help explain what drives the increase in injuries and whether such dynamics are consistent with existing theoretical models. We investigate whether entrants during recessions search more intensively (consistent with job-search models) and accumulate lower experience or tenure. Figure 6 displays the estimated effect of unemployment at entry on entrants' mobility (i.e., binary indicators for being in the entry firm, panel a; being in a firm different from that of the previous year, panel b; being out of the WHIP-Salute sample, panel d; and years of tenure in the current firm, panel c) using the same specification of equation (1) and using data from the second year of potential experience onward. ${ }^{26}$ Entrants do not exhibit a higher probability of leaving the initial firm (panel a) and are not more likely to change firms as time goes by (panel

\footnotetext{
${ }^{26}$ During the year of entry, the analyzed outcomes are the same for all workers.
}

This article is protected by copyright. All rights reserved. 
b). ${ }^{27}$
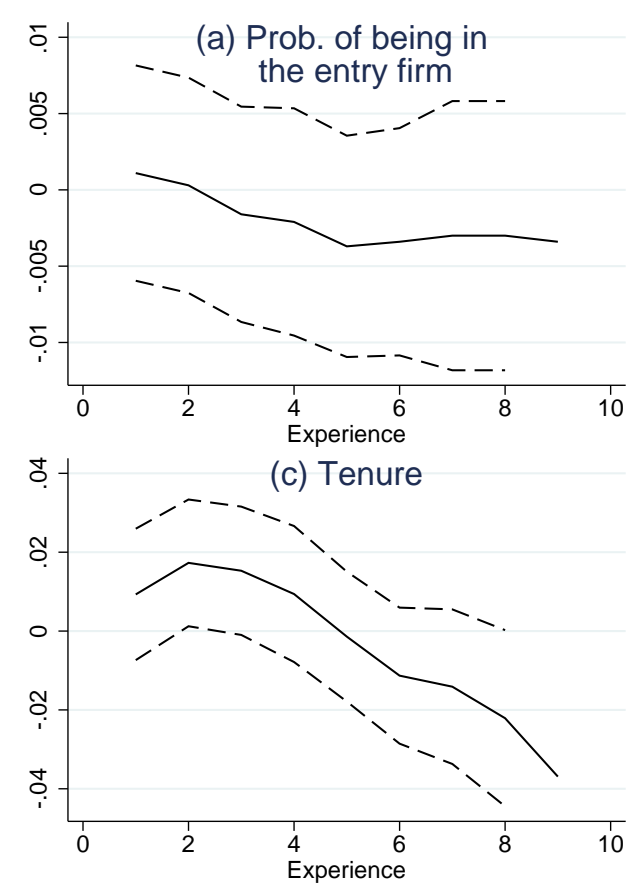

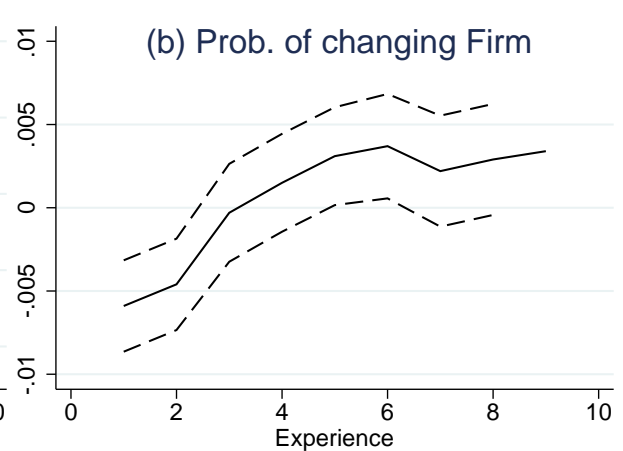

(d) Prob. Non-Employment

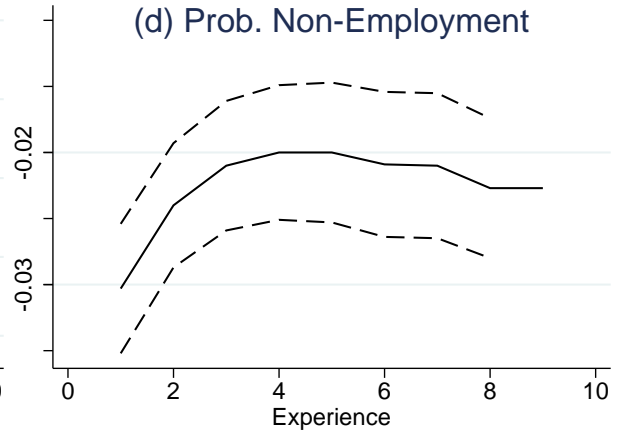

Figure 6: The effect of unemployment rate at entry on labor market transitions

Note: The solid line in the figure shows the effect of unemployment at entry $\left(u r_{0}\right)$ by year of experience (i.e. the parameters $\beta_{s}$ in equation 1) on the following dependent variables: binary indicators for being in the entry firm (panel a) and being in a firm different from that of the previous year (panel b), tenure measured as the number of years in the current firm (panel c), and non-employment status (i.e., a binary indicator for being out from the WHIP-Salute sample during the current post-entry year) (panel d). The sample uses data from the second year of potential experience onward for our sample of entrants (282,351 observations for panels a, b and c; 373,847 observations for panel d, as the dependent variable is defined also for years in which the workers are not observed in the sample). These OLS regressions include as controls the current unemployment rate $\left(u r_{i t}\right)$, calendar year effects $\left(\theta_{t}\right)$ and dummy variables for years of potential experience, $\left(\psi_{s}\right)$, for the region of birth $\left(\mu_{b}\right)$, for the region of entry $\left(\lambda_{r}\right)$, and for the year of entry cohort $\left(\gamma_{l}\right)$. All estimated coefficients are available in Table A7 in the Online Appendix. Robust standard errors in parentheses are clustered by region of entry per year of entry. The dashed lines represent the $95 \%$ confidence intervals.

These findings are in sharp contrast with the evidence for less rigid labor markets where between-firm mobility is a key ingredient for the catch-up process, particularly in the short-medium run (see for example Oreopoulos et al., 2012). Indeed, the dynamics shown in panel (c) display very tiny negative effects on tenure (lower for entrants in

\footnotetext{
${ }^{27}$ Given the nature of the data, the non-employment status may hide a transition to jobs in the public administration or to self-employment, which are not entirely covered by INPS administrative archives. However, for a young low- and medium-skilled male, these outcomes were negligible in those years.
}

This article is protected by copyright. All rights reserved. 
recessions) only in the long run. Panel (d) shows that entrants during a recession have a lower probability of being non-employed. This higher attachment to the labor market, coupled with the estimated initial wage premium and the evidence of the previous section, opposes an explanation of the losses based on the lower productivity of workers entering during a recession.

Given that we do not detect a lower accumulation of tenure or experience for entrants during recessions, our findings could, at least in part, be rationalized with the human capital mechanisms proposed by Gibbons and Waldman (2006) who suggest that, if entrants are assigned to low-quality tasks, initial conditions may have persistent effects by decreasing worker productivity. Moreover, as suggested by Oreopoulos et al. (2012), the recovery from unfavorable initial conditions may be hampered by the accumulation of specific human capital, which increases the opportunity cost to change jobs. In the Italian context, these mechanisms may be reinforced, as accumulating human capital is not merely accumulating knowledge for labor market entrants but is also an investment to become insiders. This could explain why, in contrast to other countries, during unfavorable conditions, entrants do not display a higher search intensity and do not catch-up as time passes. With respect to labor markets that are characterized by less rigid institutional settings, entrants' incentives to search for "better" jobs may be comparatively lower.

This interpretation is also supported by the estimates from a specification where the effects of experience and of initial conditions are allowed to vary for employees working in

This article is protected by copyright. All rights reserved. 
a firm that is different from the entry firm, defined as movers, with respect to stayers. ${ }^{28}$

(a) Log weekly wages

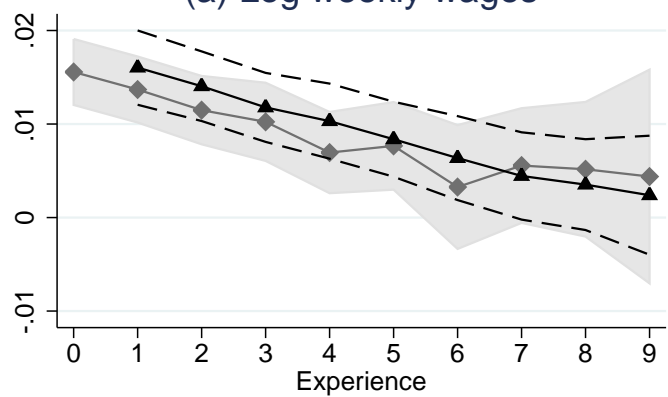

(c) NIC Injuries

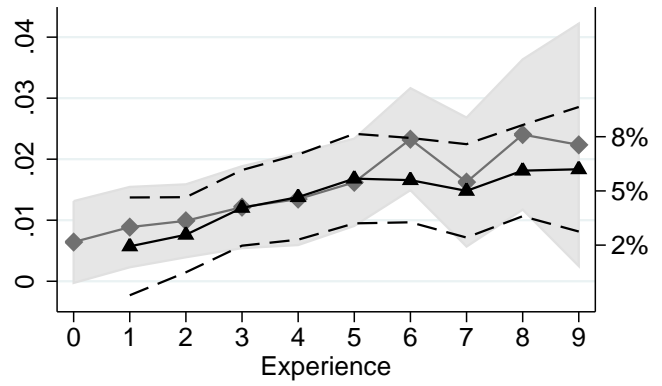

(b) All injuries

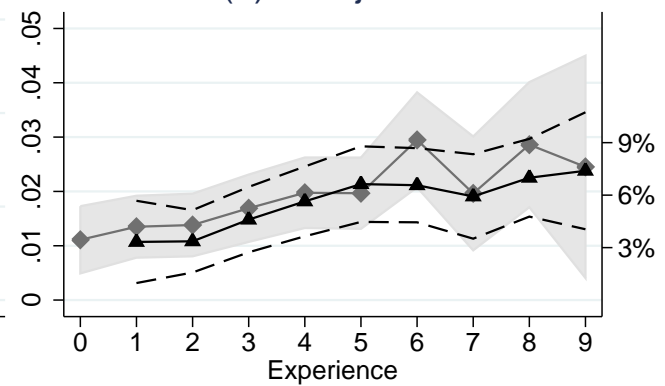

(d) IC Injuries

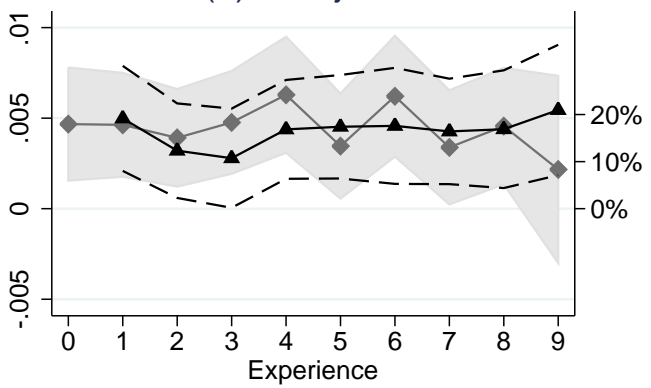

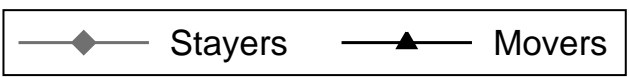

Figure 7: The effect of unemployment at entry for stayers and movers

Note: The figure reports the estimated effect of unemployment at entry $\left(u r_{0}\right)$ for stayers and movers on log weekly wages (panel a), all injuries (panel b), non-immediate care injuries (NIC in panel c), and immediate care injuries (IC in panel d). Stayers are the individuals who remain with the first employer. Movers are those individuals working in a firm that is different from the first employer. The right vertical axis expresses these effects as a percentage of the sample mean of the corresponding dependent variable. Connected diamonds represent the estimated effects of $u r_{0}$ by year of experience for stayers (i.e., the parameters $\beta_{s}$ in equation 1 where stayers are the omitted category). Connected triangles represent the estimated effects for movers. The latter are estimated as the effect of unemployment at entry (i.e., the estimated effect, $\beta_{s}$, for the omitted category, stayers) plus the coefficient of an additional interaction term, $\mathbf{1}\left[\operatorname{Exp}_{i t}=s\right] \times u_{i 0} \times$ mover $_{i t}$, included in equation 1. By construction, an individual can be a mover only after the year of entry (i.e., from year 1 onward). The regressions use the same sample of the baseline specification of Figure 2 and include the following as controls: the current unemployment rate; dummy variables for calendar year, years of potential experience, region of birth, the region of entry and year of entry cohort; and the interactions $\mathbf{1}\left[\operatorname{Exp}_{i t}=s\right] \times$ mover $_{i t}$, for $s>0$. The gray area and the dashed lines represent the $95 \%$ confidence intervals for stayers and movers, respectively. Robust standard errors are clustered by region of entry per year of entry. All estimated coefficients are available in Table A8 in the Online Appendix.

We find that movers have a relatively lower wage growth and a lower decrease in

\footnotetext{
${ }^{28}$ We use the same specification of equation 1 plus the following interactions for $s>0: \mathbf{1}\left[E x p_{i t}=s\right] \times$ ur $_{i 0} \times$ mover $_{i t}, \mathbf{1}\left[\right.$ Exp $\left._{i t}=s\right] \times$ mover $_{i t}$, where mover $_{i t}$ is an indicator variable for working in a firm that is different from the entry firm.
}

This article is protected by copyright. All rights reserved. 
injuries with experience. ${ }^{29}$ The worst evolution of movers' careers could, at least in part, be explained by lay-offs of less productive workers. Nevertheless, further considering that the estimated effect of initial labor market conditions is the same for movers and for stayers (as shown in Figure 7), our findings indicate that, on average, changes in employer are not associated with better labor market outcomes also for workers who begin with unfavorable conditions. To explain these patterns alone, job-search models and human capital models should feature prohibitive mobility costs and/or no benefits associated with job search.

\section{Conclusions}

Our results clearly identify a category of workers at higher risk of injuries during recessions. Moreover, similar to what was found by other studies analyzing differences in injuries between temporary and permanent workers (Guadalupe, 2003, Picchio and Van Ours, 2017), the observed different reporting behavior for severe and less severe accidents suggests that entrants during unfavorable macroeconomic conditions have a weak bargaining position that may lead them to underreport injuries. Therefore, authorities could improve injury prevention effectiveness by directing more controls to entrants and calibrating audits according to the business cycle. Our findings also indicate that the negative and persistent effects of unemployment at entry on job safety may depend on the institutional setting and on the rigidities of the Italian labor market. A centralized wage setting system, although decreasing differences in monetary remunerations among

\footnotetext{
${ }^{29}$ The detailed estimation results can be found in Table A8 in the Online Appendix.
}

This article is protected by copyright. All rights reserved. 
different cohorts of workers, cannot prevent the transmission of shocks to other job characteristics, particularly if these amenities are less easily measured and are less subject to bargaining and monitoring than pecuniary outcomes.

Transitions to more hazardous tasks during recessions do not necessarily entail the creation of new risks; however, they may induce a more unequal distribution of risk between different cohorts of entrants and, generally, between incumbent workers and young outsiders. A redistribution of hazardous tasks towards young workers implies that injuries will be more likely to occur at earlier stages of a career, thus exerting their negative effect over a longer period. This non-pecuniary adjustment mechanism, although enhancing flexibility at entry, may entail sizeable indirect/uninsured and human costs associated with permanent reductions in entrant's health, human capital accumulation and productivity (De Greef et al., 2011). Thus, labor market reforms that target diminishing the dualism between incumbent workers and new entrants (such as the recent changes introduced by the so-called Job Act of the Italian government, Legislative Decree No. $23 / 2015)$ and the rigidities in the wage-setting mechanisms may contribute to reducing long-lasting disparities among different cohorts of workers.

\section{References}

Beaudry, P. and DiNardo, J. (1991). The effect of implicit contracts on the movement of wages over the business cycle: Evidence from micro data. Journal of Political Economy, $99,665-88$.

Bena, A., Giraudo, M., Leombruni, R., and Costa, G. (2012). A new italian surveillance This article is protected by copyright. All rights reserved. 
system for occupational injuries: characteristics and initial results. American Journal of Industrial Medicine, 55, 584-592.

Boone, J. and van Ours, J. C. (2006). Are recessions good for workplace safety? Journal of Health Economics, 25, 1069-1093.

Boone, J., van Ours, J. C., Wuellrich, J.-P., and Zweimuller, J. (2011). Recessions are bad for workplace safety. Journal of Health Economics, 30, 764-773.

Brunner, B. and Kuhn, A. (2014). The impact of labor market entry conditions on initial job assignment and wages. Journal of Population Economics, 27, 705-738.

Cappariello, R. and Zizza, R. (2010). Dropping the books and working off the books. Labour, 24, 139-162.

Carmeci, G. and Chies, L. (2006). Education and local labour market: The case of italy. Working Papers DiSES 86, Department of Economics and Statistics, University of Trieste.

Colleoni, E., Leombruni, R., et al. (2009). Measuring skill level integrating administratrive dataset and national collective agreement archive. Technical report, LABORatorio R. Revelli, Centre for Employment Studies.

De Greef, M., Van den Broek, K., Van Der Heyden, S., Kuhl, K., and Schmitz-Felten, E. (2011). Socio-economic costs of accidents at work and work-related ill health (benoshbenefits of occupational safety and health). EU Commission.

Devereux, P. J. (2002). Occupational upgrading and the business cycle. Labour, 16, $423-452$.

This article is protected by copyright. All rights reserved. 
Genda, Y., Kondo, A., and Ohta, S. (2010). Long-term effects of a recession at labor market entry in japan and the united states. Journal of Human Resources, 45, 157-196.

Gibbons, R. and Waldman, M. (2006). Enriching a theory of wage and promotion dynamics inside firms. Journal of Labor Economics, 24, 59-108.

Guadalupe, M. (2003). The hidden costs of fixed term contracts: the impact on work accidents. Labour economics, 10, 339-357.

Hamermesh, D. S. (1999). Changing inequality in markets for workplace amenities. The Quarterly Journal of Economics, 114, 1085-1123.

Harris, M. and Holstrom, B. (1982). A theory of wage dynamics. Review of Economic Studies, 49, 315-33.

Kahn, L. B. (2010). The long-term labor market consequences of graduating from college in a bad economy. Labour Economics, 17, 303-316.

Kawaguchi, D. and Murao, T. (2014). Labor-market institutions and long-term effects of youth unemployment. Journal of Money, Credit and Banking, 46, 95-116.

Kwon, I., Milgrom, E. M., and Hwang, S. (2010). Cohort effects in promotions and wages: Evidence from sweden and the united states. Journal of Human Resources, 45.

Lindbeck, A. and Snower, D. J. (2001). Insiders versus outsiders. Journal of Economic Perspectives, 165-188.

Maclean, J. C. (2013). The health effects of leaving school in a bad economy. Journal of health economics, 32, 951-964.

OECD $(1999,2004)$. Employment outlook.

Oreopoulos, P., von Wachter, T., and Heisz, A. (2012). The short-and long-term career This article is protected by copyright. All rights reserved. 
effects of graduating in a recession. American Economic Journal: Applied Economics, 4, 1-29.

Orsi, R., Raggi, D., and Turino, F. (2014). Size, trend, and policy implications of the underground economy. Review of Economic Dynamics, 17, 417-436.

Oyer, P. (2006). Initial labor market conditions and long-term outcomes for economists. Journal of Economic Perspectives, 20, 143-160.

Picchio, M. and Van Ours, J. C. (2017). Temporary jobs and the severity of workplace accidents. Journal of safety research, 61, 41-51.

Raaum, O. and Røed, K. (2006). Do business cycle conditions at the time of labor market entry affect future employment prospects? The Review of Economics and Statistics, $88,193-210$.

Rosen, S. (1974). Hedonic prices and implicit markets: product differentiation in pure competition. Journal of political economy, 82, 34-55.

Viscusi, W. K. and Hersch, J. (2001). Cigarette smokers as job risk takers. Review of Economics and Statistics, 83, 269-280.

This article is protected by copyright. All rights reserved. 